\title{
Specification of methods and the semantics of method-oriented adverbs
}

\author{
Curt Anderson*
}

\begin{abstract}
Method-oriented adverbs have received comparatively little attention in the semantic literature on adverbs. I shed light on their semantics. These adverbs relate an event from the lexical semantics of their underlying adjective to the matrix event, and do so in a way similar to that of instruments. I use independently motivated event structure decompositions to model the interaction of adverb and verb. This study broadens our understanding of the semantics of adverbs, and how adverbial modifiers interact with the event structure of the verbs they modify.
\end{abstract}

Keywords. modification; adverbs; events; lexical semantics; frame semantics

1. Introduction. Classification and analysis of classes of adverbs has been a staple in formal semantics and syntax (see Jackendoff 1972, Geuder 2002, Schäfer 2013, Ernst 2002, and many, many others), focusing on how different classes of differ from each other in their logical and conceptual meaning, and how syntactic position influences adverb interpretation. Many subclasses of adverb have been identified (some examples in (1)), show that the category "adverb" is quite heterogenous with respect to syntactic position and semantics. Despite the large amount of work on adverbs, some classes of adverb, particularly manner adverbs and quantificational adverbs, have received more attention than others; much is still not understood about many classes of adverbs.

(1) a. arrogantly, idiotically

b. quickly, clumsily

(subject-oriented)

c. linguistically, economically

(manner)

d. possibly, occasionally

(quantificational)

One such understudied class of adverb - method-oriented adverbs - is the focus of this paper. Method-oriented adverbs (sometimes also called means-domain adverbs) characterize the method or means by which an event comes about.

(2) a. Alma categorized the plants biologically.

(Schäfer 2013)

b. Noam evaluated the data linguistically.

c. The nations intervened militarily.

These adverbs differ from manner adverbs in the way that they are paraphrased. Method-oriented adverbs are typically paraphrased using language that is typical to that of instruments, such as with use, using, and with (as in (3)), or with method or means (as in (4)). In contrast, manner adverbs are usually paraphrased with the way paraphrases, suggesting that method-oriented adverbs form a class of adverb semantically distinct from the more well-known manner adverbs.

(3) a. Alma used biological methods/principles to categorize the plants.

(Schäfer 2013)

b. Noam analyzed the data with the help of linguistic methods/tests.

*I thank Antje Roßdeutscher, Hans Kamp, Tillman Pross, Marcin Morzycki, Sebastian Löbner, Willi Geuder, Katja Gabrovska, Ai Taniguchi, the audience at Event Semantics Workshop in Heidelberg, and the audience at LSA 2019, particularly Janet Randall and Ashwini Deo, for helpful discussion. This work is supported by DFG SFB 991 (project C10). Author: Curt Anderson, Heinrich-Heine-Universität Düsseldorf (andersc@hhu.de). 
c. The nations used their militaries to intervene.

(4) This problem can only be solved using economic means.

These adverbs have received little attention in the literature on adverb semantics. Schäfer (2013) notes their existence in both English and German, and Ernst (2002) proposes a semantic representation for what he calls "means-domain adverbs," making use of a primitive means predicate and existential quantification over means as in (5). However, introducing new individuals for means only gives us a limited understand of adverbs of this sort.

(5) a. The aliens expressed themselves telepathically.

b. $\exists e[\operatorname{express}(e) \wedge \operatorname{agent}(e, \mathbf{a}) \wedge \exists x[\operatorname{means}(e, x) \wedge \operatorname{telepathic}(x)]]$

Thus, there are several goals for this paper. First, I clarify properties of method-oriented adverbs, especially with an eye towards distinguishing them from manner adverbs. Second, I relate the semantics of these adverbs to the class of relational adjectives, adjectives such as like maternal, presidential, nuclear. Third, I give an analysis of these adverbs, proposing that method-oriented adverbs link up with the event structure in a way reminiscent of instruments like with a spoon. This analysis will be couched in terms of frames, a formal semantics with structured representations for lexical and conceptual knowledge (Löbner 2014). Three case studies-diplomatically, manually, and surgically - will be developed in order to serve as a general illustration for how method-oriented adverbs relate to the modified verb.

2. Method-oriented adverbs are not manner adverbs. The first goal of this paper is to distinguish manner adverbs and method-oriented adverbs from each other. In this, there are several important ways that these adverbs differ from each other.

First, as a test for manner adverbs in English, the way paraphrases have proven to be a relatively good diagnostic for members of the class. With these paraphrases, the adjectival form of the adverb is used predicatively and predicates of a DP/NP with way as the head noun (see the examples in (6)).

(6) a. The way John fell was clumsy.

b. The way Noam evaluated the data was slow.

However, these paraphrases are systematically unavailable for method-oriented adverbs, as noted by Schäfer (2013). When these adverbs are used with these paraphrases, the resulting sentence is unacceptable. ${ }^{1}$

(7) a. *The way Noam evaluated the data was linguistic.

b. *The way Alma categorizes the plants is biological.

c. *The way Canada settled the dispute was diplomatic. (cf. evaluate linguistically)

(cf. categorize biologically)

(cf. settle diplomatically)

As Schäfer notes, the equivalent of the way paraphrases in German (Art und Weise paraphrases) are somewhat better with method-oriented adverbs than expected, but method-oriented adverbs are still distinguished from manner adverbs in wie-das-ist paraphrases (see (8) and (9)), which

\footnotetext{
${ }^{1}$ I use * to mark all cases of unacceptability, even in cases where the source is semantic.
} 
he takes to generally be a better diagnostic for manner adverbs. This again shows the distinction between the two classes.

(8) *Wie Noam die Daten auswertet, das ist linguistisch.

(Schäfer 2013) how Noam the data evaluates, that is linguistic

'The way Noam evaluates the data is linguistic.'

(9) *Wie Alma die Pflanzen kategorisiert, das ist biologisch. how Alma the plants categorizes, that is biological

(ibid.) 'The way Alma categorizes the plants is biological.'

Method-oriented adverbs differ from manner adverbs in that they are paraphrased (i) with prepositions and verbs such as use, using, and with, and (ii) with method(s) and means(s) mentioned explicitly (compared to ways with manner adverbs).

(10) a. Alma used biological methods/principles to categorize the plants.

b. Noam analyzed the data with the help of linguistic methods/tests.

c. The nations used their militaries to intervene.

(11) This problem can only be solved using economic means.

The paraphrases available to method-oriented adverbs are important here for two reasons. First, it is through the use of paraphrases that we will be able to better see how the adverb relates to the semantics of the modified verb. Second, with the paraphrase, we can see that the adverb has a paraphrase using language that is similar to that of instruments; going back at least to Lakoff (1968), use and with have been partially diagnostic of instrument meaning.

(12) a. Alma used a knife to cut the cake.

b. Noam opened the lock with a key.

c. Ted ate the cereal with a spoon

A second piece of evidence that method-oriented adverbs are distinct from manner adverbs comes from coordination. Adverbs of the same type can often be coordinated, as shown by the examples with coordinated manner adverbials in (13). Evidence that method-oriented adverbials are different from manner adverbs comes from the fact that they cannot be coordinated with manner adverbs, as shown with the data in (14).

(13) a. He evaluated the data slowly and deliberately.

b. They categorized the plants quickly and carefully.

a. *evaluate the data slowly and linguistically

b. *evaluate the data deliberately and linguistically

c. *categorize the plants thoroughly and biologically

Third, many manner adverbs are gradable; they easily allow for degree modification by modifiers such as very (see (15)). In contrast, method-oriented adverbs are non-gradable (see (16)). Note that some adverbs such as diplomatically are ambiguous between method and manner readings, but that degree modification disambiguates the adverb as being a manner adverb.

(15) a. Noam evaluated the data very quickly. 
b. Local braggarts now crow that the Americans are following in our footsteps, albeit more clumsily.

(Google)

(16) a. *Noam evaluated the data very linguistically.

b. *The nations settled the dispute more diplomatically than the citizens wanted.

c. *He turned the wheel very manually.

Finally, manner adverbs and method-oriented adverbs have different adjectival sources. Generally, manner adverbs are constructed from what I will call property adjectives; these are adjectives like quick and clumsy that can be used predicatively. Method-oriented adverbs have a different adjective source: relational adjectives (see Levi (1978), Warren (1984), McNally \& Boleda (2004), and Anderson \& Löbner (2018) for discussion of these adjectives). Relational adjectives (like $n u$ clear, maternal, and biological) often cannot be used predicatively. Semantically, they serve to further characterize a class (e.g., nuclear war is a type of war). These adjectives are often (but not always) denominal, or have a semantically related nominal (see maternal and mother).

To conclude, several diagnostics point towards method-oriented adverbs being a distinct class of adverb from manner adverbs. This raises the question of how to provide a semantics for method-oriented adverbs that can do justice to their method-specifying meaning, as well as the differences with manner adverbs discussed in this section.

\section{Method-oriented adverbs as instruments.}

3.1 Instrumental PARAPHRASES PROVIDE A Clue. If the relationship that method-oriented adverbs have to the VP is not one of manner (however we are to think of manner), then what relationship is it? We can get a better handle on the meaning of an expression by examining other expressions that have identical or nearly identical meaning-paraphrases, in other words. As pointed out previously, the paraphrases available for method-oriented adverbs differ from those of manner adverbs. Whereas manner adverbs are most commonly paraphrased using way paraphrases, method-oriented adverbs are commonly expressed with paraphrases using with, use, or using, as shown in (18) and (19). Crucially, these paraphrases have meaning identical to that of the adverbial.

(17) a. Alam categorized the plants biologically.

b. The nations solved their disagreements diplomatically.

(18) a. Alma used biological methods/principles to categorize the plants.

b. The nations used diplomacy to solve their disagreements.

(19) a. Alam categorized the plants using biological methods/with biological methods.

b. The nations solved their disagreements using diplomacy/with diplomacy.

Use, using, with often taken to be indicative of instruments (Lakoff 1968). Therefore, based on these paraphrases, I take the view that method-oriented adverbs are akin to instruments: methodoriented adverbs relate to events in a way semantically similar to how instruments relate to events.

3.2 VARIETIEs of InStruments. Not all instruments are equivalent (Van Valin \& LaPolla 1997, Koenig et al. 2008, Rissman \& Rawlins 2017); some instruments play a causal role in the event structure that they are integrated into, while other instruments play a weaker role in the event. 
These former instruments are sometimes called "causal intermediaries," due to forming a link in a causal chain between the actions of the agent and the affectedness of the patient. These instruments are the cause of some subevent within the larger event structure. Some examples of causally intermediate instruments are given in (20). The intuition with these instruments is the agent acts on the instrument, which in turns causes a change in the patient.

(20) a. Lily cut the bread with a knife.

(Rissman \& Rawlins 2017)

b. Marla dented the table with a hammer.

These instruments allow for this causal chain to be paraphrased quite readily.

(21) a. Lily used the knife, which caused bread to be cut.

b. Marla used the hammer, which caused the table to be dented.

Not all instruments play a causal role in an event; some have a weaker connection to how the event is performed. These instruments ("facilitating instruments") are part of the way the event unfolds, but are not themselves the cause of the change of state, as illustrated in (22).

a. Lucy ate the cereal with a spoon.

$\neq \ldots$ the spoon caused the cereal to be eaten

b. Martha changed the light bulb with a ladder.

$\neq \ldots$ the ladder caused the bulb to be changed

Differences in types of instruments are also manifest in what has been called the Instrument Subject Alternation (Levin 1993, Schlesinger 1989). Instruments can sometimes be promoted to subject position, as shown in (23). However, this is not freely available for all instruments; as shown in (24), some instruments cannot be promoted to subject. Facilitating instruments are not generally able to undergo the ISA, while causal intermediaries often can.

(23) a. The knife cut the bread.

b. The hammer dented the table.

(24) a. *The spoon ate the cereal.

b. *The ladder changed the light bulb.

I'll take these two phenomena-causal paraphrases and the ISA—to be diagnostics for whether an instrument is a causal intermediary or not.

3.3 Method-Oriented AdVERbs ARE nOt CAUSAL InTERmediaries. When we look at how methodoriented adverbs fit into the semantics of the sentence, what we find is that method-oriented adverbs also don't seem to denote intermediate causers. That is, although method-oriented adverbs are paraphrased using language that is remarkably similar to that of instruments, the particular individuals and events that these adverbs are related to are not part of the casual chain between agent and affected object. The lack of causal paraphrases of (25) in (26) show this, that the adverb is not linked into the event structure as a causal intermediary.

(25) a. The aliens communicated the message telepathically.

b. Noam evaluated the data linguistically. 
(26) a. *The aliens did something using telepathy, which caused the message to be communicated.

b. *Noam did something using linguistic methods, which caused the data to be evaluated.

The lack of ISA again also suggests that these adverbs are not causal intermediaries.

a. *Telepathy communicated the message.

b. *Linguistics evaluated the data.

In the following sections, I adopt aspects of the Role and Reference Grammar analysis of instruments and ISA (Van Valin \& LaPolla 1997) to frame semantics, in order to account for how these adverbs specify an event.

\section{Background.}

4.1 Frame Semantics. In this paper I adopt aspects of frame semantics. Frame semantics is a program for modeling cognitive representations, especially lexical and conceptual knowledge, using frames. These frames are inspired by and successors to frame theories developed by Fillmore (1982) and Barsalou (1992). The particular format I adopt here is closely related to those of Löbner (2014, 2017), Kallmeyer \& Osswald (2013), and Petersen (2007), who all adopt a view of frames as recursive attribute-value structures with functional attributes (e.g., type $\langle e, e\rangle$, a mapping from individuals to individuals) and values with types given in a type hierarchy. This basic framework allows for a structured semantic representation and a rich decomposition of lexical meaning into fine-grained components.

Frames are often visually presented as directed graphs, with arcs representing attributes and nodes representing values. However, frames can be equivalently represented via attribute-value matrices or first-order predicate logic formulas (see Petersen 2007 and Löbner 2017, although the details between the two differ).

Composition between frames is usually taken to be feature unification; two frames can unify if one frame subsumes the other, or if there is another frame that subsumes them both. My frame structures are given as attribute-value matrices (see discussion later in this section), but in order to clarify the relationship between frames and compositional semantics, I also use lambdas to bind variables in the frame representation when necessary, in order to clearly indicate the central node of the frame. ${ }^{2}$

4.2 Co-nouns And CO-Adjectives. The analysis of adverbs in this paper is based in part on previous work done on relational adjectives in Anderson \& Löbner 2018. Relational adjectives are adjectives such as nuclear, maternal, and technical, which serve to further classify the sort or kind denoted by the nominal they are modifying.

Although its been noted that relational adjectives are often denominal adjectives, being morphologically derived from a nominal base, we take this further in Anderson \& Löbner 2018 to argue that the crucial relationship between relational adjective and noun is semantic, not morphosyntactic. Many pairs of relational adjective and nominal are not related morphologically; examples of this include maternal and mother, royal and king/queen/prince/princess, and pulmonary and lungs. However, it is plain that there is a relationship between these words. We proposed that

${ }^{2}$ I take some inspiration from Peter Sutton (p.c.) and Hana Filip (p.c.) here. 
pairs of relational adjective and corresponding noun have the same root concept; the meaning of maternal is the same as the meaning of mother. Pairs of adjective and noun that are semantically related in this way we call co-adjectives and co-nouns.

Clearly, these words do differ in their grammatical properties. Therefore, in addition to proposing that co-noun and co-adjective have the same underlying semantics (e.g., the same frame), we propose that adjectives and nouns can differ in how their arguments are projected. These options are illustrated in (28a) and (28b) for a co-noun and a co-adjective, respectively.

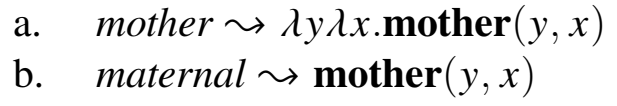

The noun mother is underlyingly relational, and it projects this argument into the syntax, along with providing a referential argument to be bound by a determiner. These two arguments are syntactically active, and this is notated via the lambdas. On the other hand, the arguments of a relational adjective are filled only through context or semantic composition; they are not syntactically active. Relational adjectives, although sharing the same core concept as their co-nouns, crucially differ in that their arguments are not projected into the syntax; these arguments must be supplied via context, or via unification with the nominal being modified.

4.3 Interlude: Semantic type explains some AdVerb Properties. The lack of a syntactically active argument position with adjectives such as maternal predicts their general unavailability in predicative position. However, relational adjectives can be used predicatively, as McNally \& Boleda (2004) point out. In order to be used predicatively, Anderson \& Löbner (2018) propose that adjectives must be coerced to have an argument position, or an additional frame be used that can itself provide an argument. A case of this is in (29), where public can be used predicatively with different senses, according to what bridging frame the concept for public is embedded in.

(29) a. This university is public.

(publically funded)

b. This restroom is public.

(accessible to the public)

This lack of a syntactically active argument position also predicts in part the paraphrases available with manner adverbs versus method-oriented adverbs. Manner adverbs, being paraphrased with the way (e.g., (30)), are used as predicates in this paraphrase: they have as their argument "ways" (however these should be ontologically conceived). The property adjectives that these adverbs are constructed from thus appear to have an open argument, licensing their appearance in predicative position.

(30) a. The way that John ran was awkward.

(cf. run awkwardly)

b. awkward $\leadsto \lambda e . \operatorname{awkard}(\operatorname{sTYLE}(e))$

Method-oriented adverbs do not admit way paraphrases precisely because they lack an argument position. In order to be used predicatively, they would need a a lambda-bound argument in their lexical semantics, and the relational adjectives that they are constructed from do not by default have this argument.

The distinction in semantic types between manner adverbs and method-oriented adverbs also explains why they cannot be coordinated. Following Munn (1993), the relevant constraint on coordination is one of semantic type, and not syntactic category. Two syntactic objects can 
be coordinated if they are of the same semantic type. For instance, John is tall and a doctor is well-formed precisely because both tall and a doctor, under standard assumptions, are type $\langle e, t\rangle$. Thus, although manner adverbs and method-oriented adverbs are syntactically of the same category, their type-theoretic differences predict that they cannot be coordinated.

4.4 Instruments And eVent Structure. Many semantic theories decompose event structure using a finite set of primitives related to temporal and aspectual notions such as activity, causation, and change of state. A change of state verb such as dry, for instance, might be represented via event structure templates like those in (31), corresponding to Hovav \& Levin (1998) and Van Valin \& LaPolla (1997) and based on Dowty's (1979) analysis of aktionsart. In both of these representations, an activity component (do' for Van Valin \& LaPolla, and ACT for Hovav \& Levin) is the cause of a change of state (BECOME).

$$
\begin{array}{ll}
\text { a. } & {\left[\mathbf{d o}^{\prime}(x, \phi)\right] \text { CAUSE }\left[\operatorname{BECOME} \mathbf{d r y}^{\prime}(y)\right]} \\
\text { b. } & {[x \mathrm{ACT}] \mathrm{CAUSE}[\mathrm{BECOME}[y \operatorname{DRY}]]}
\end{array}
$$

(Hovav \& Levin 1998)

Although frames themselves provide a natural way of encoding articulated lexical representations for verbs, the challenge for a frame semantic account is how to adapt event structure templates such as these to frames. Kallmeyer \& Osswald (2013) provide one such answer to this question; they adapt the Hovav \& Levin (1998) view of event structure by introducing a causation frame. A causation frame has two crucial attributes: a CAUSE attribute that has as its value the cause, an activity; and an EFFECT attribute that has as its value the effect (an event).

Following Kallmeyer \& Osswald (2013), a change of state verb such as dry can be rendered in a frame format as in (32) and (33), where (32a) represents the verb frame as an attribute-value matrix (AVM), (32b) represents the frame as a frame diagram (e.g., a directed graph), and (33) the same frame as a first order formula (with italics representing properties (types) and SMALL CAPs representing functional relations).

$$
\text { a. } \quad\left[\begin{array}{rl}
\text { causation } \\
\text { CAUSE } & {\left[\begin{array}{ll}
\text { activity } \\
\text { ACTOR } & x
\end{array}\right]} \\
\text { EFFECT } & {\left[\begin{array}{ll}
\text { change-of-state } \\
\text { RESULT } & {\left[\begin{array}{ll}
\text { dried-state } \\
\text { PATIENT } & y
\end{array}\right]}
\end{array}\right]}
\end{array}\right]
$$

b.

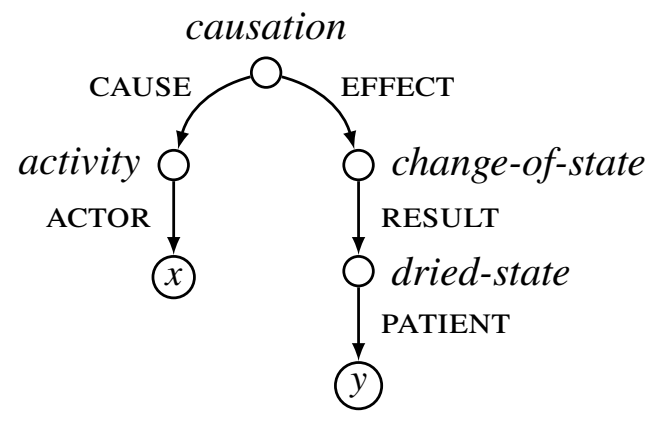

$$
\begin{aligned}
& \text { causation }(e) \wedge \operatorname{CAUSE}\left(e, e^{\prime}\right) \wedge \operatorname{EFFECT}\left(e, e^{\prime \prime}\right) \wedge \operatorname{activity}\left(e^{\prime}\right) \wedge \operatorname{ACTOR}\left(e^{\prime}, x\right) \wedge \\
& \text { change-of-state }\left(e^{\prime \prime}\right) \wedge \operatorname{RESULT}\left(e^{\prime \prime}, s\right) \wedge \text { dried-state }(s) \wedge \operatorname{PATIENT}(s, y)
\end{aligned}
$$

These representations are equivalent; attribute-value matrices can be rendered as frame diagrams, frame diagrams can be rendered as first order logical expressions, and so on. For the remainder of this paper, I will adopt AVMs as the preferred representational format, but this is purely a choice of notation and not reflecting an expressive difference between representations. 
There are different accounts for how instruments differ from each other, but much work has focused on differences in the semantics of instruments stemming from the causal role (or lack thereof) they play in an event. Van Valin \& LaPolla (1997) argue that the Instrument Subject Alternation, and hence instruments, differ based on whether they are causal intermediaries or notthat is, whether they are the effector of a causing event, or are non-effector participants of a subpart of the causing activity. Alexiadou \& Schäfer (2006) propose that the ISA is due to some instruments thematically being causers or agents. Grimm (2007) argues that thematic roles should be decomposed into finer grained properties such as sentience, volition, and instigation (the ability to bring about an event), and that clusters of these properties explain subject selection and hence the ISA, accounting for intuitions regarding different types of instruments. Koenig et al. (2008) put the focus on event structure, positing a 'help' relation between sub-events, such that acting on a facilitating instrument does not cause a change but boosts the event on some contextually supplied scales, such as ease of performance or quality of result. And, Rissman \& Rawlins (2017) argue that instruments are introduced as subevents, with an agent controlling the event.

To account for the difference between types of instruments, I will adopt the proposal from Van Valin \& LaPolla (1997). Van Valin \& LaPolla propose that causal intermediaries are participants in causing events within the event structure of the verb. Their position in the event structure allows them to be promoted to subject position in the absence of an agent.

$$
\begin{aligned}
& {\left[\mathbf{d o}^{\prime}\left(\text { Tom, }\left[\mathbf{u s e}^{\prime}(\text { Tom }, \text { knife })\right]\right)\right]} \\
& \text { CAUSE } \left.\left[\left[\mathbf{d o}^{\prime}\left(\text { knife },\left[\mathbf{c u t}^{\prime}(\text { knife }, \text { bread })\right]\right)\right] \text { CAUSE [BECOME } \text { cut }^{\prime}\left(\text { bread }^{\prime}\right)\right]\right]
\end{aligned}
$$

(Van Valin \& LaPolla 1997)

Facilitating instruments differ in their event structure, in that they are the conjunction of two eventualities under the activity operator $\mathbf{d o}^{\prime}$. Because the eventuality related to the tool is not part of the causal chain in the event structure, it is unable to be promoted to the subject.

$$
\mathbf{d o}^{\prime}\left(\text { Tom, }\left[\mathbf{e a t}^{\prime}(\text { Tom, cereal }) \wedge \mathbf{u s e}^{\prime}(\text { Tom, spoon })\right]\right)
$$

(Van Valin \& LaPolla 1997)

Van Valin \& LaPolla (1997) state that $\wedge$ is "being used here as a conjunction for joining the component logical structures referring to substates-of-affairs that make up the macro-state-of-affairs denoted by the entire logical structure" (Van Valin \& LaPolla 1997: 656, note 18). Adapting this to my frame account, I reinterpret this as making an assertion that the two event structure components are forming a complex eventuality linked by the same ACTOR argument. That is, the use of $\wedge$ signifies the formation of a complex event from subevents.

I represent Van Valin \& LaPolla's analysis of implements in a frame using the schema in (36). In this frame, the two event structure components forming part of the causing activity are linked to the causing activity via a PART-OF attribute. Space precludes a full exploration of how eat and use are related to each other in the the meaning of eat with a knife, but there is some that we can say something about this activity. This activity is a mereologically complex event, with eat and use proper subevents of this event. Moreover, these subevents are also not totally ordered temporally; eat and use must be at least overlapping in their runtimes. 


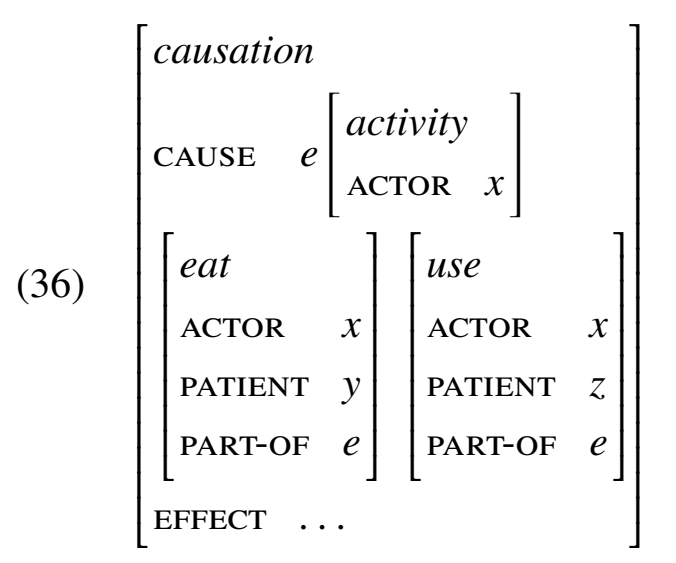

In comparison, instruments that are causal intermediaries can be given a frame structure that makes use of recursively organized causation frames; the value of the EFFECT node of the head causation frame will be a second causation frame.

5. Case studies. In order to illustrate the account, I present in this section three case studies: diplomatically, manually, and surgically. The first case study, diplomatically, serves to illustrate a clear case where methods come directly from the lexical semantics of the adjective (via the nominal it is derived from). The second, manually, illustrates a case where a bridging frame provide by context is necessary to link the method-oriented adverb to the VP in the appropriate way. Finally, surgically illustrates in a more general way how lexical information plays a role in deriving the meaning of the method-oriented adverb.

5.1 Diplomatically. The first case study will be the adverb diplomatically, illustrated with the example in (37). In line with Anderson \& Löbner's (2018) proposal that the conceptual core of many pairs of relational adjectives and nominals is the same, we can analyze diplomatic as having a frame structure that is like that of the word diplomat. This move also seems relatively natural, in that diplomatic is obviously derivationally related to the word diplomat.

(37) Canada settled the dispute diplomatically.

Following a line of thought that many nominals related to professions and social roles include reference to events in their lexical representations (Vendler 1968, Larson 1998, Anderson \& Löbner 2018), I also analyze diplomat as making reference to events, what I'll simply call diplomaticactivity events. When instantiated, events of working in an embassy, meeting with other diplomats and leaders, negotiating treaties, and so on are all events that fall under this type. It is participation in these sorts of events and permission to engage in them that define a diplomat. The frame for diplomat is provided in (38).

$$
\text { diplomat } \leadsto \lambda x\left[\begin{array}{ll}
\text { diplomatic-activity } \\
& \\
\text { ACTOR } & x\left[\begin{array}{ll}
\text { diplomat } \\
\text { FROM } & {[\text { nation }]} \\
\text { TO } & {[\text { nation }]}
\end{array}\right]
\end{array}\right]
$$


When a method-oriented adverb is used, the information contributed by the adverb must be merged with the information contributed by the VP, in this case settle the dispute. ${ }^{3}$ In the absence of a clear predicate-argument relationship between the adverb frame and the VP frame, frame unification is the method for merging these two frames together.

How does unification of the frame for diplomat and of the VP settled the dispute occur? I'll suppose that settled the dispute underlyingly has a causative frame of the form shown earlier in (32a). A frame of this sort provides two relevant ways for the diplomat frame to unify. First, the diplomatic-activity frame could subsume the less specified activity subframe, which would also in turn specify the ACTOR attribute of the causing activity, due to the ACTOR of diplomatic-activity being diplomats themselves. (39) illustrate this possibility. However, it seems that additional contextual information in the sentence-namely, the specification of an ACTOR in the sentence already, e.g. Canada-make this unification unlikely.

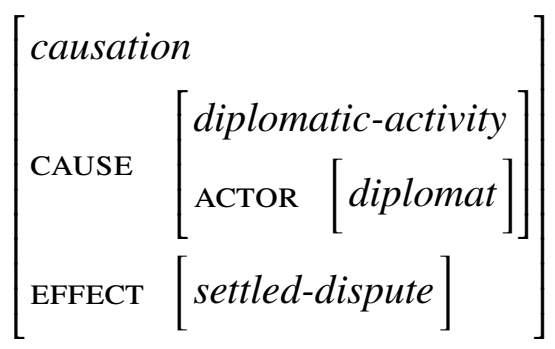

The second possibility makes use of a minimal bridging frame that can facilitate the unification of the VP and the adverb. This frame will be an activity frame with a PART-OF attribute which I will assume to be freely available in the semantics. ${ }^{4}$

$$
\left[\begin{array}{ll}
\text { activity } & \\
\text { PART-OF } & e
\end{array}\right]
$$

(PART-OF bridging frame)

Application of the bridging frame to the frame for diplomatically results in an event description of diplomatic-activity that is asserted to be part of some other event, shown in (41).

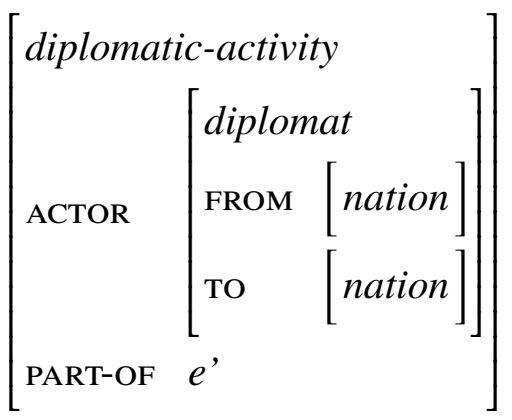

Identifying this event with the activity portion of the causation event denoted by the verb (e.g., the value of the CAUSE attribute) allows us to unify diplomatically with the VP. In this way, the adverb diplomatically specifies an aspect of the activity portion of the VP.

\footnotetext{
${ }^{3} \mathrm{I}$ 'm assuming for now that these adverbs are merged as VP adjuncts, but nothing crucial hinges on this.

${ }^{4}$ This is in some ways reminiscent of a typeshift, in that it's an operation to rescue semantic compositionality.
} 
5.2 ManUALLY. Manually presents a good case study of an adverb where the base adjective does not seem to specify events; in order to interpret manually, a bridging frame provided via world knowledge or context needs to used in conjunction with the frame provided by the base adjective.

I take the co-noun for the adjective manual to be hand. Evidence for this comes from the observation that manually has the paraphrase by hand. Minimally, the frame for hand has an attribute for the owner of the hand, and the type hierarchy specifies it as a type of object.

$$
\text { manually } \leadsto\left[\begin{array}{ll}
\text { hand } & \\
\text { OWNER } & x
\end{array}\right]
$$

$B y$ is also able to further specify the method or means by which an event is performed. Collocations of by and manually provide additional support that the lexical content of manually is actually quite underspecified, and is only further specified through context.

(43) a. sort and clean the seeds [...] manually, by sieving or blowing away the debris

b. silenced manually at any time by operating levers

c. This kind of map analysis used to be done manually [...] by overlaying transparent map sheets

d. it was to be driven manually by turning the big wheel

I analyze these as the by phrase providing a subevent structure within the causing activity. Taking (43d) as our example, manually specifies that it is a hand that causes the turn of a wheel, giving this a causal structure. This is illustrated in (44).

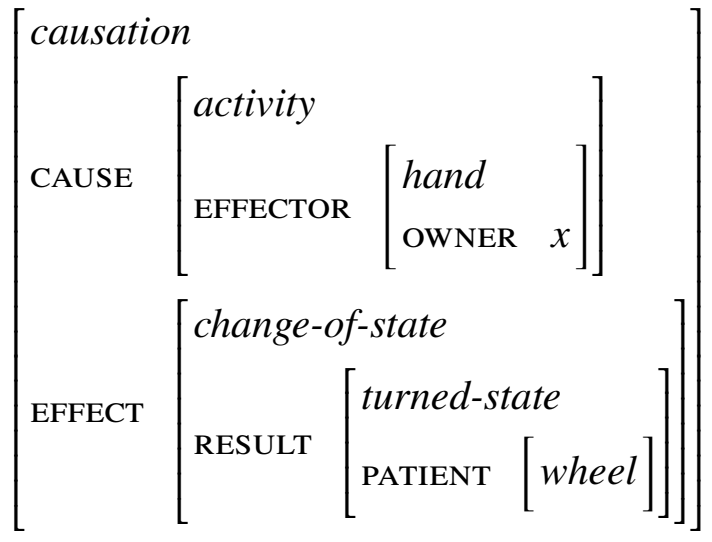

What to do with this eventuality? For concreteness, let's assume that causation events are not a subtype of activities, and thus that a causation frame cannot be the value of a CAUSE attribute. Even supposing it were a type of activity, the semantics would be wrong: a driving event is not solely characterized by turning the wheel of a vehicle. By helping ourselves to the PART-OF bridging frame and unifying this frame with the event of a hand causing the wheel to turn, however, we find a licit unification. Unification can proceed by taking the causing of a wheel to be turned as a subevent in the activity component of the driving. This representation also predicts the unavailability of hand (the co-noun of manual) to arise as a subject in ISA (e.g., *The hand drove the car) due to hand never being part of a causal chain with the PATIENT of the verb being modified. 
5.3 Surgically. The last case study I will consider here is surgically, which is derived from the adjective surgical, which is in turn has as its co-noun surgery. First, the difficulty with surgery is that it itself is very atypical as an instrument. It is somewhat degraded to try to directly use surgery as an instrument, as the examples in (45) show.

a. We removed John's nose surgically.

b. ??We removed John's nose with surgery.

c. ??We used surgery to remove John's nose.

The difficult, I suspect, is that surgery is an event noun; it does not denote an object, but rather denotes a type of event. Since use and with require access to an object to be used, rather than an event, there is a clash between the conceptual and or semantic types required by the verb and preposition and contributed by the DP.

However, I do not think that this precludes the type of analysis pursued in the previous sections. The style of analysis pursued here presupposed rich lexical information, and the rich lexical information encoded in the concept of surgery that makes it possible for it to be used as a methodoriented adverb. First, it's necessary to provide a semantics for the co-noun surgery. Surgery is an event noun, and (setting aside details regarding genericity), we can provide a meaning for surgery that has it making reference to certain kinds of activities.

$$
\text { surgery } \leadsto \lambda e\left[\begin{array}{c}
e\left[\begin{array}{ll}
\text { surgery } & \\
\text { AGENT } & x \\
\text { LOCATION } & {[\text { operating-room }}
\end{array}\right]
\end{array}\right]
$$

What do we do with this representation? As in our previous examples, it must be linked to the activity component of the verbal meaning, the CAUSE attribute. However, there are two possibilities here, and it is not clear that the grammar disambiguates between them.

The first possibility is to apply the freely available PART-OF bridging frame to the lexical representation of surgery. When this occurs, the bridging frame is unified with the activity component of surgery. It's through this attribute, the PART-OF attribute, that the surgery activity is linked to the activity contributed by the VP (e.g., doing something that results in removing someone's nose). One prediction of this unification is that should allow for the possibility that some individuals doing the removal are not surgeons, only that surgeons participated in a part of the entire removal process. This prediction is made because it is not obligatory to identify the ACTOR of the activity of the main verb with the ACTOR of a subpart of the activity. This seems to hold, as shown in (47). This is a wide shot of the event, encompassing not just the immediate surgery, but also the other individuals and acts that supported it in different ways.

(47) We removed John's nose surgically, but I played no direct part in it's removal. 
The second possibility for unification is to identify the surgery activity directly with the CAUSE. This effectively narrows the viewpoint of the event to just the surgery. In doing so, the actors of the main activity are identified with actors in a surgery activity. The lexical specification of surgery requires that these participants be surgeons themselves. This also appears to be a reading of the sentence in (45a); when the perspective of the event is narrowed to only the surgical event, there is a corresponding contraction of the types of the individuals that can participate in that event as actors, namely only surgeons.

6. Conclusion. This paper forms the basis for a better understanding of a particular class of understudied VP adverbs, method-oriented adverbs. As I've argued, method-oriented adverbs are not manner adverbs, differing in both their syntactic and semantic properties. There are several basic contributions this paper makes to our understanding of method-oriented adverbs, and to an understanding of adverbs generally. First, that method-oriented adverbs related to the VP in a way similar to the way that certain instruments relate to the VP. Method-oriented adverbs related to the VP they modify as non-causal intermediaries. In a frame semantics inspired by Role and Reference Grammar event structure templates (Van Valin \& LaPolla 1997), these adverbs specify aspects of the activity component of an event. Second, the lexical semantics of the adjectival base of the adverb plays an important role in how the adverb relates to the VP. In particular, eventualities from the lexical semantics of the adjective or from a contextually supplied bridging relation are linked with the activity component in the event structure of the verb. Finally, this paper shows how a decompositional theory of meaning, such as frame semantics, provides a level of detail that makes a compositional analysis of the contribution of modifiers possible.

\section{References}

Alexiadou, Artemis \& Florian Schäfer. 2006. Instrument subjects are agents or causers. In Donald Baumer, David Montero \& Michael Scanlon (eds.), Proceedings of the 25th West Coast Conference on Formal Linguistics, 40-48. Somerville, MA: Cascadilla.

Anderson, Curt \& Sebastian Löbner. 2018. Roles and the compositional semantics of roledenoting relational adjectives. In Uli Sauerland \& Stephanie Solt (eds.), Proceedings of Sinn und Bedeutung 22.91-108.

Barsalou, Lawrence. 1992. Frames, concepts, and conceptual fields. In Adrienne Lehrer \& Eva Feder Kittay (eds.), Frames, fields, and contrasts: New essays in semantic and lexical organization. 21-74. Hillsdale, New Jersey: Lawrence Erlbaum Associates.

Dowty, David. 1979. Word meaning and Montague grammar: the semantics of verbs and times in Generative Semantics and in Montague's PTQ. Dordrecht: Springer.

Ernst, Thomas. 2002. The syntax of adjuncts. Cambridge: Cambridge University Press.

Fillmore, Charles J. 1982. Frame semantics. In The Linguistic Society of Korea (ed.), Linguistics in the morning calm. Seoul: Hanshin Publishing Company.

Geuder, Wilhelm. 2002. Oriented adverbs: Issues in the lexical semantics of event adverbs. Universität Tübingen dissertation.

Grimm, Scott. 2007. The bounds of subjecthood: Evidence from instruments. Annual meeting of the Berkeley Linguistics Society 33. 178-189. https://doi.org/10.3765/bls.v33i1.3526. 
Hovav, Malka Rappaport \& Beth Levin. 1998. Building verb meanings. In Miriam Butt \& Wilhelm Geuder (eds.), The projection of arguments: Lexical and compositional factors. 97134. CSLI Publications Stanford.

Jackendoff, Ray. 1972. Semantic interpretation in generative grammar. Cambridge, MA: MIT Press.

Kallmeyer, Laura \& Rainer Osswald. 2013. Syntax-driven semantic frame composition in Lexicalized Tree Adjoining Grammars. Journal of Language Modelling 1(2). 267-330.

Koenig, Jean-Pierre, Gail Mauner, Breton Bienvenue \& Kathy Conklin. 2008. What with? the anatomy of a (proto)-role. Journal of Semantics 25(2). 175-220. DOI: 10.1093/jos/ffm013.

Lakoff, George. 1968. Instrumental adverbs and the concept of deep structure. Foundations of language 4(1). 4-29.

Larson, Richard K. 1998. Events and modification in nominals. In Devon Strolovitch \& Aaron Lawson (eds.), Proceedings of Semantics and Linguistic Theory 8, 145-168.

Levi, Judith N. 1978. The syntax and semantics of complex nominals. New York: Academic Press.

Levin, Beth. 1993. English verb classes and alternations: a preliminary investigation. Chicago: University Of Chicago Press.

Löbner, Sebastian. 2014. Evidence for frames from human language. In Thomas Gamerschlag, Doris Gerland, Rainer Osswald \& Wiebke Petersen (eds.), Frames and concept types. 23-67. Dordrecht: Springer.

Löbner, Sebastian. 2017. Frame theory with first-order comparators: Modeling the lexical meaning of punctual verbs of change with frames. In Helle Hvid Hansen, Sarah E. Murray, Mehrnoosh Sadrzadeh \& Henk Zeevat (eds.), Logic, language, and computation: 11th international Tbilisi symposium on logic, language, and computation. 98-117. Dordrecht: Springer.

McNally, Louise \& Gemma Boleda. 2004. Relational adjectives as properties of kinds. In O. Bonami \& P. Cabredo Hofherr (eds.), Empirical issues in formal syntax and semantics 5, 179-196.

Munn, Alan. 1993. Topics in the syntax and semantics of coordinate structures: University of Maryland dissertation.

Petersen, Wiebke. 2007. Representation of concepts as frames. The Baltic International Yearbook of Cognition, Logic and Communication 2. 151-170.

Rissman, Lilia \& Kyle Rawlins. 2017. Ingredients of instrumental meaning. Journal of Semantics 34(3). 507-537.

Schäfer, Martin. 2013. Positions and interpretations: German adverbial adjectives at the syntaxsemantics interface. Berlin: De Gruyter Mouton.

Schlesinger, Izchak M. 1989. Instruments as agents: on the nature of semantic relations. Journal of Linguistics 25(1). 189-210. https://doi.org/10.1017/S0022226700012147.

Van Valin, Robert D. \& Randy J. LaPolla. 1997. Syntax: Structure, meaning and function. Cambridge: Cambridge University Press.

Vendler, Zeno. 1968. Adjectives and nominalizations. The Hague: Mouton.

Warren, Beatrice. 1984. Classifying adjectives. Göteborg: Acta Universitatis Gothoburgensis. 